\title{
CORRESPONDENCE
}

Correspondents are asked to be brief

\section{Doctors in South Africa}

I. N. Bernadt, F.R.C.S.

Female Sterility Produced by Investigation

F. W. Wright, F.F.R., and Sir John Stall-

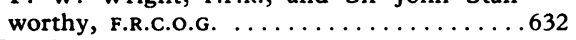

Measles

S. R. Saxena, M.D. . . . . . . . . . . . . 632

Analgesics and the Kidney

I. C. Calder, PH.D., and others.........6633

Irradiation Treatment of Rheumatoid

Arthritis

J. M. Gumpel, M.R.c.P. . . . . . . . . .6633

Survival in Coalworkers' Pneumoconiosis

B. Curry, M.sc..............633

Edrophonium in Diagnosis of Cholinergic Crisis

D. L. McLellan, M.R.C.P. . . . . . . . .6634

Sterility after Vasectomy

I. L. Craft, F.R.C.S., and others; G. J.

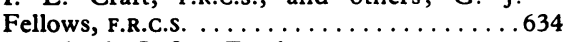

Anaesthetic Safety Devices

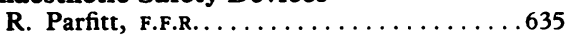

Nephrotoxic Drugs

B. M. Tune, M.D., and R. L. Kempson,

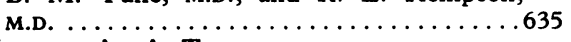

Hypotension in Tetanus

B. Fistein, M.R.C.P.ED., D.T.M.\&H. . . . . . 635
Rubella Surveillance: Recent Data from

Scotland

N. R. Grist, F.R.C.P.ED., F.R.C.PATH. . . . . .636

Treatment of Diabetic Retinopathy

W. G. Oakley, F.R.C.P.; E. N. Wardle,

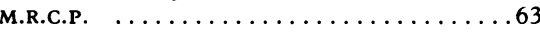

Neonatal Jaundice and Maternal Oxytocin

Infusion

A. Ghosh, M.R.C.P., and F. P. Hudson,

F.R.C.P.ED.; W. G. Mills, F.R.C.o.G.; M. C. R.

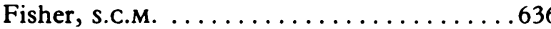

Apnoea after Sacral Extradural Analgesia

J. A. Lee, F.F.A.R.C.S. . . . . . . . . . . 637

Delayed Attacks of Malaria in Visitors to

the Tropics

T. Wilson, M.D. ; L. J. Bruce-Chwatt, M.D. . 637

Specific Immunoglobulin for Prevention

of Serum Hepatitis

D. N. S. Kerr, F.R.C.P. . . . . . . . . . .6637

Hazards of Laparoscopy

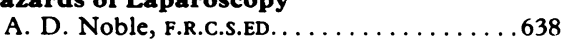

Depression and Organic Disorder

G. Dodds, M.B...............638

Protection of Cytomegalovirus-infected Cells by IgG Antibody

P. Diosi, M.D., and Georgeta Herzog. . . . 638
Endotoxic Shock Complicating Transhepatic Cholangiography

B. B. Hickey, F.R.C.S. . . . . . . . . . .6638

Antibiotic-induced Meningitis

W. I. H. Shedden, M.D.............6638

Hypomagnesaemia after Parathyroidectomy

R. D. M. Scott, M.R.C.P., and J. A. Strong,

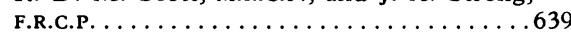

Incidence and Prevalence

R. Ulman, M.R.C.P. . . . . . . . . . . . . 6639

Impatient Patients

D. H. Ryde, M.R.C.G.P. . . . . . . . . . . .6639

Aetiology of Reye's Syndrome

P. G. B. Johnston, M.R.C.P.; A. Elkeles,

M.D. . . . . . . . . . . . . . . . . 640

Erudition and Aphorisms

J. Apley, F.R.C.P............. . .6640

Problem Oriented Record Card

P. R. V. Tomson, M.R.C.G.P... . . . . . . .640

Diuretics and Renal Pain

N. G. Kounis, M.D. . . . . . . . . . .641

Conference of Royal Colleges and Faculties in Scotland

J. H. Croom, P.R.C.P.ED., and others . . .6.641

\section{Doctors in South Africa}

SIR,-The list of salary scales, set out in the Table below, is taken from a recent advertisement in the South African Medical fournal for doctors in one of the provincial administrations. You will notice the differential salary scale, in which coloured and Asian medical officers and registrars receive from $76 \%$ to $81 \%$, and African doctors $61 \%$ to $74 \%$, of the white doctors' salaries. Similar salary scales exist in all state hospitals, in all provincial hospials and in most municipal hospitals. Nurses' salary scales are equally discriminatory. TABLE-Minimum and Maximum Commencing Annual Appropriate Experienie

\section{Medical: White}

Principal specialist

Senior specialist

N.B. To the ranks mentioned hereunder a pensionable allowance of $15 \%$ inrespect of Whites and $17 \mathrm{~J} \%$ "in respect of nonWhites are payable on the basic salary of full-time personnel with effect from 1 April 1973.

\section{Specialis}

Senior superintendent

Senior medical officer

Medical officer

Registrar

(Must be qualified for at least two years)

(Must be qualified for at least (Rand:p.a.) $\begin{array}{ll}12,600 & \text { (fixed) } \\ 12,000 \text { (fixed) }\end{array}$

two years)

II. Medical: Coloured $/$ Asian

Registrar
Medical officer :

$\begin{array}{ll}4,350 & 6,600 \\ 4,350 & 6,600\end{array}$

III. Medi-aal: Non-White

Registrar
Medical officer

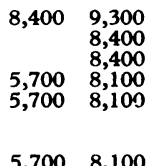

This must be a unique situation in the world.
Though no law prevents coloured doc tors from issuing instructions to white nurses, this is not allowed in provincial and state hospitals. Coloured doctors are not allowed to visit white wards. Any coloured colleague from Britain would not be able to attend ward rounds in the white wards of South African teaching hospitals.

The South African Medical Association has frequently condemned these discriminatory practices, but has apparently not done much more about it.

The South African College of Medicine has not commented on this situation, as far as I know, but coloured and African candidates for the college examinations ar never allowed to examine white patients in their practicals.

The comments of the B.M.A., the royal colleges, and your readers would be most interesting. It is only by exposing this re markable situation that the combined weight of informed opinion may be mobilized to exert pressure to effect change.-I am, etc.,

Cape Town, South Africa

IAN BERNADT

**The B.M.f. has now stopped accepting advertisements from South Africa unless assured that no discriminatory salary attaches to the post advertised.-ED., B.M.F.

\section{Female Sterility Produced by Investigation}

SIR,-Some doctors still use iodized oil as the contrast medium for hysterosalpingography. It has serious disadvantages in that oil embolism is a danger and deaths have

form following peritoneal reaction to the iodized oil. This can be clinically silent and detected later by repeat hysterosalpingography, laparoscopy, or at laparotomy. On the other hand, there can be an acute reaction with a clinical picture of pelvic peritonitis. When unsuspected pelvic tuberculosis is present we have seen violent reactions with pelvic abscess formation.

We have investigated several patients with bilateral tubal occlusion which appeared to develop at the fimbrial end of the tubes following hysterosalpingography using iodized oil. Normal tubal patency had been confirmed at the initial examination.

We consider oil contrast media for hysterosalpingography to be both dangerous and unnecessary. It is tragic, and there could be medicolegal consequences, when a technique demonstrating normal tubal patency causes subsequent sterility. In reminding doctors of the possible complications of injecting iodized oil into the peritoneal cavity we recommend the use of water soluble contrast media, which do not have any of these disadvantages and which allow a quicker, more certain, and less dangerous demonstration of tubal anatomy and patency. -We are, etc.,

F. W. WRIGHT JOHN STALLWORTHY

Churchill Hospital,

Churchill
Oxford been reported, and pelvic adhesions may

SIR,-I am glad that the question of pathogenesis of measles has been raised in your leading article (28 July, p. 187). Despite the advent of measles vaccine this disease remains a challenging problem for the treating doctor, especially in India. 